\title{
PERFIL SOCIODEMOGRÁFICO E PSICOSSOCIAL DE MULHERES COM DEPRESSÃO PÓS-PARTO: UMA REVISÃO INTEGRATIVA
}

\author{
SOCIODEMOGRAPHIC AND PSYCHOSOCIAL PROFILE OF WOMEN WITH \\ POST-DEPARTMENT DEPRESSION: AN INTEGRATING REVIEW \\ Marcos Vinícius Vieira Barros ${ }^{\mathrm{a}^{*}}$, Ricardo Saraiva Aguiar ${ }^{\mathrm{b}^{*}}$ \\ marcosvini0998@gmail.com ${ }^{\text {a }}$, ricardo.aguiar@docente.unip.br ${ }^{\text {b }}$ \\ Universidade Paulista, Campus Brasília-DF*
}

\section{RESUMO}

Data de recebimento do artigo: 26/12/2018

Data de aceite do artigo: 18/02/2019

Introdução: A depressão pós-parto é um transtorno de humor que apresenta uma incidência dos sintomas nas mulheres no período de quatro a seis semanas após o nascimento da criança, atingindo seu ápice aos seis meses após o parto. Objetivo: Identificar as características sociodemográficas, psicossociais e dados sobre o pré-natal, parto e puerpério mais prevalentes nas mulheres que apresentaram sintomatologia sugestiva ou foram diagnosticadas com depressão pós-parto. Materiais e Métodos: Trata-se de uma revisão integrativa da literatura realizada no período de 2013 a 2018, através do levantamento de artigos nas bases de dados LILACS e Scielo. Resultados: Foram selecionados 20 artigos científicos. Esses abordaram assuntos que foram separados e organizados por categoria onde foi consolidado o conhecimento publicado através dos mesmos acerca do tema proposto, interligando-os sintaticamente a fim de obter um conjunto de proposições e conclusões dos autores escolhidos. Conclusões: Ao analisar os estudos, foi possível confirmar a relação da depressão pós-parto com a interrupção precoce da amamentação e dificuldades de realizar a mesma, complicações na gestação e no parto, escolaridade baixa, não planejamento da gravidez, histórico tanto pessoal quanto familiar de transtornos mentais e relacionamento conjugal conflituoso. Porém, tanto as variáveis que se correlacionaram quanto as variáveis que não conseguirem estabelecer uma associação com a depressão não podem ser excluídas de estudos futuros e da avaliação na assistência de saúde, pois é importante sempre estar atento às mudanças na correlação das mesmas com a doença.

Palavras-chave: Depressão pós-parto; depressão; fatores de risco; saúde da mulher

\section{ABSTRACT}

Introduction: Postpartum depression is a mood disorder that presents an incidence of symptoms in women within four to six weeks after the child's birth, reaching its apex six months postpartum. Objective: To identify the most prevalent sociodemographic, psychosocial and prenatal, puerperal and puerperal data in women who presented suggestive symptomatology or who were diagnosed with postpartum depression. Materials and Methods: This is an integrative review of the literature carried out in the period from 2013 to 2018, through the survey of articles in the LILACS and SciELO databases. Results: Twenty scientific articles were selected. These addressed subjects that were separated and organized by category where the knowledge published through them was consolidated about the proposed theme, interconnecting them syntactically in order to obtain a set of propositions and conclusions of the chosen authors. Conclusions: When analyzing the studies, it was possible to confirm the relationship between postpartum depression and early interruption of breastfeeding and difficulties to perform it, complications during pregnancy and childbirth, low schooling, no pregnancy planning, both personal and family history of mental disorders and conflicting marital relationship. However, both the variables that correlate and the variables that can not establish an association with depression can not be excluded from future studies and evaluation in health care, since it is important to always be aware of the changes in their correlation with the disease.

Keywords: Depression postpartum; depression; risk factors; women's health 


\section{Introdução}

A depressão é uma síndrome psiquiátrica que apresenta uma ampla prevalência, acometendo de 3 a $5 \%$ da população ${ }^{1}$. É uma das principais causas de mudanças drásticas nas necessidades de saúde, apontada pela Organização Mundial de Saúde (OMS), nos próximos 20 anos $^{2}$. No ano de 2004, a depressão já era considerada como a terceira motivação de morbidade mundial, demonstrando a capacidade de atingir a primeira colocação em $2030^{3}$.

As mulheres apresentam até duas vezes mais riscos de desenvolverem depressão e durante o período em que estão responsáveis pelo cuidado de seus filhos esse número tende a se enfatizar ${ }^{3}$. As transformações hormonais, físicas e emocionais no período gravídico-puerperal podem afetar positivamente o desenvolvimento dessa enfermidade ${ }^{4}$.

Após o nascimento da criança, um episódio ou a soma de vários episódios depressivos é caracterizado como depressão pós-parto (DPP $)^{4}$. A DPP é um transtorno de humor que apresenta uma incidência dos sintomas nas mulheres no período de quatro a seis semanas após o nascimento da criança, atingindo seu ápice aos seis meses após o parto $^{5}$. Os sintomas da DPP são semelhantes aos da depressão, ou seja, são muitos os sintomas que podem caracterizá-la, no entanto, alguns são mais comuns, como anedonia, falta de energia, sentimento de culpa, alterações de humor, alterações do sono, choro frequente, diminuição do apetite, desinteresse, alteração do nível de funcionamento hormonal e da libido ${ }^{4}$.

Estudos apontam que a prevalência de DPP encontra-se entre 7,2 e 39,4\%, respectivamente nas cidades de Recife-PE e Vitória-ES 5 . Além do mais, um estudo no período de 2011-2012, mostrou que mais de um quarto das mulheres brasileiras apresentam sintomas típicos de depressão entre 6 e 18 meses após o nascimento da criança $a^{6}$.

Nesse sentido, as mulheres depressivas tendem a apresentar comportamento recluso e introvertido, gerando um ambiente de insensibilidade e falta de atenção à segurança, saúde e necessidades psicológicas da criança ${ }^{7}$. Outrossim, os inúmeros sintomas da DPP, além de afetarem a saúde da mulher, podem interferir negativamente no crescimento e desenvolvimento da criança, em um período em que há a necessidade de cuidados es- pecíficos de suma importância para um desenvolvimento saudável.

Tendo por consideração que os sintomas da DPP podem trazer consequências no vínculo mãe-bebê, este artigo faz-se importante para conhecer a população prevalente destes sinais e sintomas, estudando como se comportam conforme as variáveis sociodemográficas e psicossociais a fim de direcionar ações de saúde à esse grupo, facilitando a assistência prestada às mulheres e assim podendo prover um ambiente mais seguro para um desenvolvimento saudável da criança.

Desta forma, esse estudo tem como objetivo identificar as características sociodemográficas, psicossociais e dados sobre o pré-natal, parto e puerpério mais prevalentes nas mulheres que apresentaram sintomatologia sugestiva ou foram diagnosticadas com DPP, através da análise e separação dessas características.

À vista disso, é esperado encontrar, de acordo com as variáveis sociodemográficas e psicossociais e informações sobre a gestação, parto e puerpério, os parâmetros mais frequentes em mães diagnosticadas ou que apresentem a sintomatologia referente a depressão pós-parto. Com esses dados espera-se montar um perfil epidemiológico e psicossocial de mães relacionado a esta enfermidade, mostrando resultados mais relevantes em variáveis como satisfação conjugal e planejamento da gravidez.

\section{Materiais e métodos}

Trata-se de revisão integrativa da literatura que atualmente tem sido uma ferramenta muito importante na elaboração de estudos no campo da saúde, pois busca colher e reunir de forma sucinta informações das pesquisas disponíveis sobre determinado assunto.

Para determinar quais estudos seriam incluídos nesta pesquisa, os meios adotados para a identificação de questões relevantes, bem como as informações a serem extraídas de cada estudo selecionado, iniciou-se o processo na definição da pergunta norteadora, que é considerada a fase mais importante da revisão. Dessa forma, seguiram-se as fases para a elaboração de revisão integrativa da literatura, onde foi iniciada a pri- 
meira etapa do processo com a definição e seleção da hipótese para a definição do tema. Nessa fase obteve-se a seguinte pergunta norteadora: Qual o perfil socidemográfico e psicossocial das mulheres com depressão pós-parto?

Para a obtenção dos artigos, foi realizado um levantamento em bancos de dados eletrônicos da Literatura Latino-Americana e do Caribe em Ciências da Saúde (LILACS) e Scientific Electronic Library Online (Scielo). A busca foi realizada a partir do descritor: "Depressão pós-parto" entre o período de 2013 a 2018 e apenas artigos disponíveis em português. A seleção do descritor utilizado no processo de revisão foi efetuada mediante consulta ao DECS - descritores em ciências da saúde - da Biblioteca Virtual em Saúde (BVS).

Para responder a pergunta norteadora, foram adotados critérios de inclusão, sendo incluídos no estudo os artigos cujo acesso ao periódico era livre aos textos completos, artigos em idioma português, publicados e indexados nos últimos seis anos (2013 a 2018), que foram localizados através da busca com o seguinte descritor: "Depressão pós-parto" que estavam relacionados à temática das "variáveis psicossociais e sociodemográficas da depressão pós-parto".

Foram utilizados como critério de exclusão artigos publicados em anos anteriores a 2013, em idiomas que não o português, que não possuíam relação com o tema proposto ao estudo e a pergunta norteadora e artigos que não continham informações sociodemográficas e psicossociais disponíveis, além de que, optou-se por não incluir teses, dissertações e monografias, visto que a realização de uma busca sistemática das mesmas é inviável logisticamente.

Com a utilização dos parâmetros, foram encontrados 193 artigos no banco de dados da LILACS e 111 artigos no banco de dados da Scielo. Para os resultados de cada busca, a seleção inicial ocorreu pela simples leitura dos títulos encontrados, sendo excluídos aqueles que evidentemente não se relacionavam ao tema; idioma em português; bem como o ano de publicação. Para os potencialmente elegíveis, os resumos foram avaliados para uma segunda etapa de seleção quanto à elegibilidade.

Os artigos que aparentemente cumpriam com os critérios de inclusão, neste caso, 31 artigos foram obtidos e analisados na íntegra. Após a leitura criteriosa, apenas 20 artigos, atenderam rigorosamente aos critérios de inclusão.

\section{Resultados}

\section{DESCRIÇÃO GERAL DOS ARTIGOS SELECIONADOS}

Na tabela 1 estão descritas as informações dos 20 artigos incluídos nesta revisão integrativa. Foram interpretados e sintetizados todos os resultados, através de uma comparação dos dados evidenciados na análise dos artigos ao referencial teórico.

Tabela 1. Distribuição dos artigos de acordo com o título, autores, objetivo, método, conclusão, ano de publicação.

\begin{tabular}{|c|c|c|c|c|c|c|}
\hline & Título & Autor & Objetivo & Método & Conclusão & Ano \\
\hline Artigo 1 & $\begin{array}{c}\text { A relação } \\
\text { mãe-bebê } \\
\text { no contexto } \\
\text { Depressão Pós- } \\
\text {-parto: Estudo } \\
\text { qualitativo }^{16}\end{array}$ & $\begin{array}{c}\text { Greinert BRM, } \\
\text { Carvalho ER, } \\
\text { Capel H, Mar- } \\
\text { ques AG, Milani } \\
\text { RG }\end{array}$ & $\begin{array}{l}\text { analisar como a } \\
\text { sintomatologia } \\
\text { depressiva em } \\
\text { mulheres no pe- } \\
\text { ríodo pós-parto } \\
\text { influencia na re- } \\
\text { lação mãe-bebê. }\end{array}$ & $\begin{array}{c}\text { Pesquisa quali- } \\
\text { tativa }\end{array}$ & $\begin{array}{l}\text { Conclui-se que } \\
\text { a mulher no } \\
\text { período graví- } \\
\text { dico-puerperal } \\
\text { necessita de } \\
\text { apoio e suporte } \\
\text { psicológico, a } \\
\text { fim de reconhe- } \\
\text { cer, prevenir e } \\
\text { intervir sobre os } \\
\text { fatores que in- } \\
\text { terferem na sua } \\
\text { saúde mental e } \\
\text { promover o de- } \\
\text { senvolvimento } \\
\text { saudável da rela- } \\
\text { ção mãe-bebê. }\end{array}$ & 2018 \\
\hline
\end{tabular}


Artigo 2

Sintomas
depressivos
em puérperas
atendidas em
unidades de saú-
de da família ${ }^{23}$

de da família ${ }^{23}$

Melo SB, Jordão

RRR, Guimarães

FJ, Perrelli JGA,

Cantilino A,

Sougey EB

\section{Evidências de sintomatologia depressiva no pós-parto ime- diato $^{20}$ \\ Artigo 3}

Artigo 4

Depressão pós-parto e tipo de parto: Perfil de mulheres atendidas em um hospital escola $^{22}$

analisar a
prevalência
dos sintomas
da depressão e
suas associações
com caracte-
rísticas sociais,
econômicas,
comportamen-
tais, psicológicas
e obstétricas
no pós-parto
imediato.

Estudo transversal, descritivo e probabilístico. ledo OR, David

FL, Avelino MM, Moraes EV
Biscegli TS, Silva GS, Romualdo
PF, Oliveira
MS, Silva BR, Solim F

identificar
a depressão
pós-parto (DPP)
entre mulheres
atendidas em
Unidades de
Saúde da Famí-

Estudo transver-

sal quantitativo

lia (USF).

\footnotetext{
Descrever a prevalência de depressão pós-parto e verificar a associação com o tipo de parto.
}

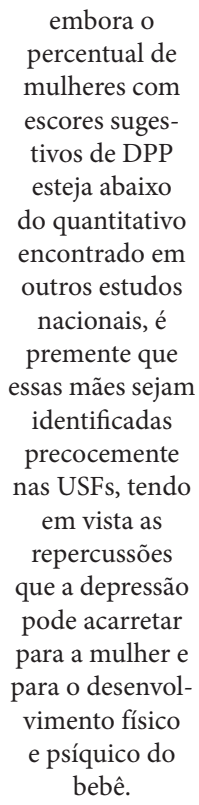

A prevalência de sintomas depressivos no puerpério imediato foi elevada (24,51\%). Além disso, adver-

te-se para um forte indicativo de associação entre sintomas da depressão pós-parto e o uso de tabaco, ter familiar com problema mental, a sogra interferir nos cuidados do recém-nascido, morar de aluguel e sofrer violência psicológica/ emocional.

2018

$$
\begin{aligned}
& \text { A prevalência } \\
& \text { de DPP foi com- } \\
& \text { patível com a } \\
& \text { média nacional } \\
& \text { e não foi obser- } \\
& \text { vada associação } \\
& \text { com o tipo de } \\
& \text { parto. }
\end{aligned}
$$




\begin{tabular}{|c|c|c|c|c|c|c|}
\hline Artigo 5 & $\begin{array}{l}\text { Depressão } \\
\text { entre puérperas: } \\
\text { prevalência e fa- } \\
\text { tores associados }{ }^{3}\end{array}$ & $\begin{array}{c}\text { Hartmann JM, } \\
\text { Mendoza-sassi } \\
\text { RA, Cesar JA }\end{array}$ & $\begin{array}{c}\text { medir a } \\
\text { prevalência e } \\
\text { identificar fato- } \\
\text { res associados } \\
\text { à ocorrência } \\
\text { de depressão } \\
\text { entre puérperas } \\
\text { residentes em } \\
\text { um município } \\
\text { de médio porte } \\
\text { no extremo Sul } \\
\text { do país }\end{array}$ & $\begin{array}{l}\text { Estudo transver- } \\
\text { sal, censitário. }\end{array}$ & $\begin{array}{c}\text { Os dados } \\
\text { apresentados } \\
\text { mostraram a } \\
\text { necessidade de } \\
\text { novas ações na } \\
\text { atenção às ges- } \\
\text { tantes, principal- } \\
\text { mente durante } \\
\text { a realização do } \\
\text { pré-natal, vi- } \\
\text { sando a oferecer } \\
\text { à mulher um } \\
\text { acompanhamen- } \\
\text { to mais global } \\
\text { de sua gestação, } \\
\text { assim como o } \\
\text { suporte social e } \\
\text { profissional de } \\
\text { que necessita } \\
\text { naquele mo- } \\
\text { mento. }\end{array}$ & 2017 \\
\hline Artigo 6 & $\begin{array}{l}\text { Perfil epide- } \\
\text { miológico } \\
\text { de puérperas } \\
\text { com quadro } \\
\text { de Depressão } \\
\text { pós-parto, em } \\
\text { unidades de um } \\
\text { município da } \\
\text { serra catarinen- } \\
\text { se, } \mathrm{SC}^{21}\end{array}$ & $\begin{array}{l}\text { Santos MAR, } \\
\text { Goetz ER, Sicco } \\
\text { GP, Fernandes } \\
\text { HGS, Medeiros } \\
\text { M, Melo NEB } \\
\text { et al }\end{array}$ & $\begin{array}{l}\text { traçar e analisar } \\
\text { o perfil epide- } \\
\text { miológico da } \\
\text { população de } \\
\text { puérperas aten- } \\
\text { didas pelas Uni- } \\
\text { dades de Saúde } \\
\text { pesquisadas. }\end{array}$ & $\begin{array}{l}\text { Estudo de corte } \\
\text { transversal e } \\
\text { pesquisa quanti- } \\
\text { tativa }\end{array}$ & $\begin{array}{l}\text { Pôde-se concluir } \\
\text { que o perfil } \\
\text { epidemiológico } \\
\text { necessitaria de } \\
\text { mais entrevistas } \\
\text { para ser aten- } \\
\text { dido. }\end{array}$ & 2017 \\
\hline
\end{tabular}




\begin{tabular}{|c|c|c|c|c|c|c|}
\hline & Título & Autor & Objetivo & Método & Conclusão & Ano \\
\hline Artigo 8 & $\begin{array}{l}\text { Tristeza materna } \\
\text { em puérperas e } \\
\text { fatores associa- } \\
\operatorname{dos}^{18}\end{array}$ & $\begin{array}{l}\text { Silva MAP, De- } \\
\text { mitto M, Agnolo } \\
\text { C, Torres M, } \\
\text { Carvalho M, } \\
\text { Pelloso S }\end{array}$ & $\begin{array}{c}\text { Analisar a } \\
\text { presença de } \\
\text { sintomas de } \\
\text { tristeza materna } \\
\text { vivenciados } \\
\text { por puérperas } \\
\text { e seus fatores } \\
\text { associados. }\end{array}$ & $\begin{array}{l}\text { estudo transver- } \\
\text { sal, quantitativo }\end{array}$ & $\begin{array}{l}\text { O alto percentu- } \\
\text { al de mulheres } \\
\text { que apresenta- } \\
\text { ram sintomas } \\
\text { depressivos } \\
\text { justifca a } \\
\text { importância e } \\
\text { necessidade de } \\
\text { cuidados com a } \\
\text { saúde mental da } \\
\text { mulher no perí- } \\
\text { odo gestacional } \\
\text { e puerperal, } \\
\text { visto que são } \\
\text { períodos de } \\
\text { vulnerabilidade } \\
\text { e transformação. }\end{array}$ & 2017 \\
\hline Artigo 9 & $\begin{array}{l}\text { Depressão } \\
\text { pós-parto e } \\
\text { autoeficácia } \\
\text { materna para } \\
\text { amamentar: } \\
\text { prevalência e } \\
\text { associação }^{8}\end{array}$ & $\begin{array}{l}\text { Abuchaim ESV, } \\
\text { Caldeira NT, } \\
\text { Lucca MM, Va- } \\
\text { rela M, Silva IA }\end{array}$ & $\begin{array}{l}\text { Identificar a } \\
\text { prevalência de } \\
\text { sintomas de } \\
\text { depressão pós- } \\
\text {-parto e o nível } \\
\text { de autoeficácia } \\
\text { para amamentar, } \\
\text { entre puérperas } \\
\text { atendidas em } \\
\text { um Centro de } \\
\text { Incentivo ao } \\
\text { Aleitamento } \\
\text { Materno, e ana- } \\
\text { lisar possíveis } \\
\text { associações. }\end{array}$ & $\begin{array}{l}\text { Estudo trans- } \\
\text { versal }\end{array}$ & $\begin{array}{l}\text { Prevalência } \\
\text { elevada de sinto- } \\
\text { mas de depres- } \\
\text { são pós-parto e } \\
\text { de autoeficácia } \\
\text { para ama- } \\
\text { mentar foram } \\
\text { evidenciados } \\
\text { na população } \\
\text { estudada. Os ní- } \\
\text { veis de sintomas } \\
\text { de depressão } \\
\text { pós-parto e de } \\
\text { autoeficácia } \\
\text { revelaram asso- } \\
\text { ciação de causa e } \\
\text { efeito entre si. }\end{array}$ & 2016 \\
\hline Artigo 10 & $\begin{array}{c}\text { Sintomas } \\
\text { depressivos no } \\
\text { período puerpe- } \\
\text { ral: identificação } \\
\text { pela escala } \\
\text { de depressão } \\
\text { pós-parto de } \\
\text { Edinburgh }^{14}\end{array}$ & $\begin{array}{c}\text { Boska GA, } \\
\text { Wisniewski D, } \\
\text { Lentsck MH }\end{array}$ & $\begin{array}{l}\text { Identificar sinto- } \\
\text { mas depressivos } \\
\text { e associá-los às } \\
\text { características } \\
\text { sociodemográ- } \\
\text { ficas e clínicas } \\
\text { de mulheres } \\
\text { no puerpério } \\
\text { tardio. }\end{array}$ & $\begin{array}{l}\text { Estudo trans- } \\
\text { versal }\end{array}$ & $\begin{array}{l}\text { A depressão } \\
\text { pós-parto } \\
\text { considerada um } \\
\text { problema de } \\
\text { saúde pública } \\
\text { esteve presente } \\
\text { entre algumas } \\
\text { mulheres, mere- } \\
\text { cendo atenção e } \\
\text { importância da } \\
\text { equipe multidis- } \\
\text { ciplinar das Uni- } \\
\text { dades Básicas de } \\
\text { Saúde. }\end{array}$ & 2016 \\
\hline
\end{tabular}




\begin{tabular}{|c|c|c|c|c|c|c|}
\hline Artigo 11 & $\begin{array}{l}\text { Depressão } \\
\text { pós-parto e } \\
\text { satisfação con- } \\
\text { jugal: impacto } \\
\text { longitudinal em } \\
\text { uma amostra } \\
\text { brasileira }^{11}\end{array}$ & $\begin{array}{c}\text { Hollist CS, Fal- } \\
\text { ceto OG, Seibel } \\
\text { BL, Springer } \\
\text { PR, Nunes NA, } \\
\text { Fernandes CLC } \\
\text { et al }\end{array}$ & $\begin{array}{c}\text { Verificar a } \\
\text { relação entre a } \\
\text { satisfação conju- } \\
\text { gal e a depressão } \\
\text { pós-parto e o } \\
\text { impacto destas } \\
\text { variáveis nos ní- } \\
\text { veis de satisfação } \\
\text { conjugal e de- } \\
\text { pressão futuros, } \\
\text { em uma amostra } \\
\text { brasileira. }\end{array}$ & $\begin{array}{l}\text { Estudo longitu- } \\
\text { dinal }\end{array}$ & $\begin{array}{l}\text { Os resultados } \\
\text { indicam que o } \\
\text { modelo teórico } \\
\text { que estabelece } \\
\text { a relação entre } \\
\text { conflito conjugal } \\
\text { e depressão } \\
\text { é também } \\
\text { apropriado para } \\
\text { casais brasilei- } \\
\text { ros, sugerindo } \\
\text { a utilização } \\
\text { potencial da } \\
\text { terapia de casal } \\
\text { no tratamento } \\
\text { da depressão } \\
\text { pós-parto no } \\
\text { Brasil. }\end{array}$ & 2016 \\
\hline Artigo 12 & $\begin{array}{l}\text { Maternidade } \\
\text { e trabalho: } \\
\text { Associação } \\
\text { entre Depressão } \\
\text { pós-parto, apoio } \\
\text { social e satisfa- } \\
\text { ção conjugal }^{19}\end{array}$ & $\begin{array}{l}\text { Manent MV, Ro- } \\
\text { drigues OMPR }\end{array}$ & $\begin{array}{l}\text { Descrever, entre } \\
\text { mães trabalha- } \\
\text { doras, ainda em } \\
\text { licença materni- } \\
\text { dade, aspectos } \\
\text { sociodemográfi- } \\
\text { cos da mãe e do } \\
\text { bebê, e aspectos } \\
\text { relacionados } \\
\text { à gestação, ao } \\
\text { puerpério e ao } \\
\text { bebê. }\end{array}$ & $\begin{array}{l}\text { Estudo trans- } \\
\text { versal }\end{array}$ & $\begin{array}{l}\text { Verificou-se } \\
\text { satisfação com } \\
\text { o apoio social } \\
\text { disponível e } \\
\text { preservação } \\
\text { da satisfação } \\
\text { conjugal. Os } \\
\text { resultados } \\
\text { apontam para } \\
\text { a importância } \\
\text { de atendimento } \\
\text { psicológico à } \\
\text { mulher na gesta- } \\
\text { ção e puerpério, } \\
\text { assim como } \\
\text { esclarecê-las de } \\
\text { seus direitos. }\end{array}$ & 2016 \\
\hline Artigo 13 & $\begin{array}{l}\text { Depressão } \\
\text { pós-parto entre } \\
\text { mulheres com } \\
\text { gravidez não } \\
\text { pretendida }^{9}\end{array}$ & $\begin{array}{c}\text { Brito CNO, } \\
\text { Alves SV, Luder- } \\
\text { mir AB, Araújo } \\
\text { TVB }\end{array}$ & $\begin{array}{c}\text { Analisar a } \\
\text { associação } \\
\text { entre gravidez } \\
\text { não pretendida } \\
\text { e depressão } \\
\text { pós-parto }\end{array}$ & $\begin{array}{l}\text { Estudo transver- } \\
\text { sal de coorte }\end{array}$ & $\begin{array}{l}\text { Gravidez não } \\
\text { pretendida mos- } \\
\text { trou-se associa- } \\
\text { da a sintomas } \\
\text { depressivos após } \\
\text { o parto. Isso } \\
\text { sugere que valo- } \\
\text { res elevados na } \\
\text { Edinburgh Post- } \\
\text { natal Depression } \\
\text { Screening Scale } \\
\text { podem resultar } \\
\text { de gravidez não } \\
\text { pretendida. }\end{array}$ & 2015 \\
\hline
\end{tabular}




\begin{tabular}{|c|c|c|c|c|c|}
\hline Artigo 14 & $\begin{array}{l}\text { Depressão } \\
\text { pós-parto: uma } \\
\text { compreensão } \\
\text { psicossocial. Re- } \\
\text { vista Psicologia: } \\
\text { Teoria e Prática }{ }^{24}\end{array}$ & $\begin{array}{l}\text { Greinert BRM, } \\
\text { Milani RG }\end{array}$ & $\begin{array}{c}\text { Identificar os } \\
\text { fatores psicosso- } \\
\text { ciais que podem } \\
\text { favorecer o } \\
\text { desenvolvimen- } \\
\text { to da depressão } \\
\text { pós-parto } \\
\text { (DPP). }\end{array}$ & $\begin{array}{l}\text { Pesquisa trans- } \\
\text { versal }\end{array}$ & $\begin{array}{c}\text { Conclui-se que } \\
\text { são necessários } \\
\text { programas de } \\
\text { prevenção da } \\
\text { DPP que levem } \\
\text { em considera- } \\
\text { ção os fatores } \\
\text { psicossociais } \\
\text { descritos, os } \\
\text { quais poderiam } \\
\text { ser desenvolvi- } \\
\text { dos durante a } \\
\text { gravidez, pois } \\
\text { as alterações } \\
\text { físicas, emocio- } \\
\text { nais e sociais } \\
\text { já começam } \\
\text { a florescer na } \\
\text { futura mãe. }\end{array}$ \\
\hline
\end{tabular}

\begin{tabular}{|c|c|c|c|c|c|c|}
\hline & Título & Autor & Objetivo & Método & Conclusão & Ano \\
\hline Artigo 15 & $\begin{array}{l}\text { Fatores psi- } \\
\text { cossociais e } \\
\text { sociodemográ- } \\
\text { ficos associados } \\
\text { à depressão } \\
\text { pós-parto: Um } \\
\text { estudo em hos- } \\
\text { pitais público } \\
\text { e privado da } \\
\text { cidade de São } \\
\text { Paulo, Brasil }{ }^{12}\end{array}$ & $\begin{array}{l}\text { Morais MLS, } \\
\text { Fonseca LAM, } \\
\text { David VF, Vie- } \\
\text { gas LM, Otta E }\end{array}$ & $\begin{array}{l}\text { Avaliar o efeito } \\
\text { de diversos } \\
\text { fatores socio- } \\
\text { demográficos } \\
\text { e psicossociais } \\
\text { sobre a ocor- } \\
\text { rência de DPP } \\
\text { em mulheres } \\
\text { cujos partos } \\
\text { ocorreram em } \\
\text { dois hospitais } \\
\text { da cidade de } \\
\text { São Paulo: um } \\
\text { público e outro } \\
\text { privado. }\end{array}$ & $\begin{array}{l}\text { Pesquisa trans- } \\
\text { versal }\end{array}$ & $\begin{array}{c}\text { Análise de } \\
\text { regressão } \\
\text { envolvendo } \\
\text { características } \\
\text { psicossociais das } \\
\text { participantes re- } \\
\text { velou associação } \\
\text { positiva de DPP } \\
\text { com depressão } \\
\text { anterior e com } \\
\text { frequência de } \\
\text { conflitos com } \\
\text { o parceiro e } \\
\text { relação negativa } \\
\text { com anos de } \\
\text { escolaridade e } \\
\text { escore de apoio } \\
\text { social. }\end{array}$ & 2015 \\
\hline Artigo 16 & $\begin{array}{l}\text { Prevalência e } \\
\text { fatores de risco } \\
\text { relacionados } \\
\text { a depressão } \\
\text { pós-parto em } \\
\text { salvador }{ }^{25}\end{array}$ & $\begin{array}{c}\text { Oliveira MJM, } \\
\text { Dunningham W }\end{array}$ & $\begin{array}{c}\text { Calcular a } \\
\text { prevalência } \\
\text { de Depressão } \\
\text { Pós-Parto em } \\
\text { mulheres acom- } \\
\text { panhadas no } \\
\text { Ambulatório de } \\
\text { Puericultura do } \\
\text { Hospital Mar- } \\
\text { tagão Gesteira, } \\
\text { no período de } \\
\text { junho de } 2012\end{array}$ & $\begin{array}{l}\text { Estudo observa- } \\
\text { cional descritivo } \\
\text { e analítico }\end{array}$ & $\begin{array}{l}\text { A alta prevalên- } \\
\text { cia de depressão } \\
\text { pós-parto en- } \\
\text { contrada reforça } \\
\text { seu significado } \\
\text { como problema } \\
\text { de saúde pú- } \\
\text { blica, exigindo } \\
\text { estratégias de } \\
\text { prevenção e } \\
\text { tratamento. }\end{array}$ & 2015 \\
\hline
\end{tabular}




\begin{tabular}{|c|c|c|c|c|c|c|}
\hline Artigo 17 & $\begin{array}{l}\text { Incidência } \\
\text { de depressão } \\
\text { pós-parto no } \\
\text { município de } \\
\text { Campos dos } \\
\text { Goytacazes }^{17}\end{array}$ & $\begin{array}{c}\text { Silva DD, } \\
\text { Bernardes } \\
\text { DR, Carva- } \\
\text { lho DTC, } \\
\text { Bittencourt } \\
\text { GRBVR, } \\
\text { Portugal JCA }\end{array}$ & $\begin{array}{c}\text { Avaliar a } \\
\text { inci- } \\
\text { dência de } \\
\text { depressão } \\
\text { pós-parto na } \\
\text { maternidade } \\
\text { do Hospital } \\
\text { dos Plan- } \\
\text { tadores de } \\
\text { Cana (HPC) } \\
\text { no município } \\
\text { de Campos } \\
\text { dos Goyta- } \\
\text { cazes, bem } \\
\text { como seus } \\
\text { principais } \\
\text { fatores de } \\
\text { risco. }\end{array}$ & $\begin{array}{l}\text { Estudo des- } \\
\text { critivo }\end{array}$ & $\begin{array}{l}\text { A prevalên- } \\
\text { cia encon- } \\
\text { trada da } \\
\text { patologia foi } \\
6 \% \text { do quan- } \\
\text { titativo de } \\
\text { parturientes } \\
\text { pesquisadas. }\end{array}$ & 2015 \\
\hline Artigo 18 & $\begin{array}{l}\text { Avaliação da } \\
\text { Depressão Pós- } \\
\text {-parto: Preva- } \\
\text { lência e fatores } \\
\text { associados }^{15}\end{array}$ & $\begin{array}{c}\text { Soares YKC, } \\
\text { Gonçalves NPC, } \\
\text { Carvalho CMS }\end{array}$ & $\begin{array}{c}\text { Conhecer a } \\
\text { prevalência e } \\
\text { fatores associa- } \\
\text { dos à depressão } \\
\text { pós-parto (DPP) } \\
\text { em puérperas de } \\
\text { uma materni- } \\
\text { dade pública no } \\
\text { município de } \\
\text { Teresina-PI. }\end{array}$ & $\begin{array}{l}\text { Estudo descriti- } \\
\text { vo exploratório }\end{array}$ & $\begin{array}{l}\text { Constata-se a } \\
\text { alta prevalência } \\
\text { da DPP, o que } \\
\text { requer mudança } \\
\text { no modelo } \\
\text { assistencial des- } \\
\text { tinado à mulher } \\
\text { no ciclo gravídi- } \\
\text { co-puerperal, a } \\
\text { fim de promover } \\
\text { prevenção desta } \\
\text { doença e pro- } \\
\text { mover a saúde } \\
\text { materna. }\end{array}$ & 2015 \\
\hline Artigo 19 & $\begin{array}{l}\text { Dor e fatores } \\
\text { associados em } \\
\text { puérperas de- } \\
\text { primidas e não } \\
\text { deprimidas }^{10}\end{array}$ & $\begin{array}{l}\text { Angelo RCO, } \\
\text { Sabino LF, } \\
\text { Schwingel PA, } \\
\text { Lima APO, } \\
\text { Zambaldi CF, } \\
\text { Cantilino A et al }\end{array}$ & $\begin{array}{c}\text { Verificar a } \\
\text { associação entre } \\
\text { dor e depressão } \\
\text { pós-parto. }\end{array}$ & $\begin{array}{c}\text { Estudo analítico, } \\
\text { de delineamento } \\
\text { transversal }\end{array}$ & $\begin{array}{c}\text { Dor de } \\
\text { intensidade } \\
\text { moderada a } \\
\text { intensa aumenta } \\
\text { a probabilidade } \\
\text { de mulheres } \\
\text { desenvolve- } \\
\text { rem sintomas } \\
\text { depressivos no } \\
\text { pós-parto. }\end{array}$ & 2014 \\
\hline Artigo 20 & $\begin{array}{l}\text { Análise da de- } \\
\text { pressão pós-par- } \\
\text { to no período } \\
\text { puerperal e sua } \\
\text { relação com } \\
\text { o aleitamento } \\
\text { materno }^{13}\end{array}$ & $\begin{array}{c}\text { Matos JM, } \\
\text { Silva VLQ, Rosa } \\
\text { WAG, Oliveira } \\
\text { ISB }\end{array}$ & $\begin{array}{c}\text { Identificar a } \\
\text { presença de } \\
\text { depressão } \\
\text { pós-parto, no } \\
\text { período puerpe- } \\
\text { ral, de mulheres } \\
\text { cadastradas } \\
\text { na Estratégia } \\
\text { de Saúde da } \\
\text { Família (ESF), } \\
\text { no município } \\
\text { de Jacuí- MG } \\
\text { e avaliar suas } \\
\text { interferências na } \\
\text { amamentação. }\end{array}$ & $\begin{array}{l}\text { Pesquisa descri- } \\
\text { tiva quanti-qua- } \\
\text { litativa }\end{array}$ & $\begin{array}{c}\text { Foi possível } \\
\text { constatar que } \\
\text { embora se tenha } \\
\text { o aleitamen- } \\
\text { to materno } \\
\text { presente, ele } \\
\text { não está sendo } \\
\text { realizado em sua } \\
\text { totalidade, pois } \\
\text { pode estar sobre } \\
\text { a interferência } \\
\text { indireta da } \\
\text { depressão pós- } \\
\text {-parto. }\end{array}$ & 2013 \\
\hline
\end{tabular}

Fonte: Os autores (2018). 
A partir da análise do conteúdo, foi possível identificar os estudos de acordo com as variáveis abordadas sobre a depressão pós-parto e categorizá-los em: amamentação, complicações na gravidez/parto, escolaridade, estado civil, gravidez planejada, histórico de transtornos, idade, relacionamento conjugal, renda familiar e tipo de parto. A maioria dos artigos abordou mais de uma categoria, sendo que apenas 5 deles (25\%) abordaram apenas uma categoria.

\section{Discussão}

\section{AMAMENTAÇÃO}

Na literatura científica já está bem estabelecido os benefícios da amamentação tanto para a saúde da mãe quanto para a da criança. Seguindo essa linha de raciocínio, os artigos 1, 7, 9, 19 e 20 abordam sobre a relação entre amamentação e a DPP, dessa forma, foi observado que todos eles relatam, em especial, a influência da DPP na amamentação

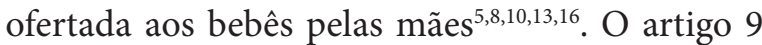
enfatiza a associação da autoeficácia materna para amamentar, mensurada no estudo através da Breastfeeding Self-Efficacy Scale (BSES), com a sintomatologia depressiva encontrada nas mães, mensurada através da Escala de Depressão Pós-Parto de Edimburg (EPDS) ${ }^{8}$.

O artigo 1 aborda a relação entre a mãe e o bebê no contexto da DPP, reunindo relatos de mães que tiveram essa experiência ${ }^{16}$. A amamentação abrange fortemente o vínculo afetivo da mãe-bebê, uma vez que é considerado o primeiro contato do recém-nascido com o campo exterior. As mães deste estudo apresentaram dificuldades no processo de amamentação e, por conta disso, mostraram-se bastante frustradas e angustiadas, sentimentos esses relacionados a doença ${ }^{16}$.

$\mathrm{O}$ artigo 7 aborda, principalmente, o aleitamento materno exclusivo (AME) do recém-nascido até seu terceiro mês de vida. As mães que demonstraram sintomas depressivos mostraram uma chance 1,63 vezes relativamente maior de interrupção precoce do AME. O fator idade também manifestou associação com o AME, visto que foi observado uma tendência em mulheres mais jovens da interrupção do AME precocemente ${ }^{5}$.
No artigo 9, foi observado que sintomas moderados e altos mensurados na EPDS diminuem, respectivamente, em $27,4 \%$ e $38,8 \%$ os níveis de autoeficácia materna na amamentação. Essa relação de sintomas apontados pela EPDS e amamentação também foi apontado no artigo 20, onde foi possível constatar nas puérperas com sintomas moderados uma maior prevalência de amamentação mista ${ }^{8,10}$.

O artigo 19 foi considerado a exceção dos artigos, visto que na maior parte dos estudos que abordavam o tema foi constatada uma relação negativa entre a DPP e a amamentação, evidenciado pela dificuldade na amamentação e a interrupção do AME, apesar de não ser uma diferença tão numerosa, o número de puérperas que não amamentavam foi percentualmente maior nas puérperas não-deprimidas $(5,6 \%)$ se comparado as puérperas deprimidas $(3,8 \%)^{10}$.

De modo geral, é importante que o profissional da saúde fique atento a amamentação da puérpera depressiva, principalmente se ela apresenta dificuldades e auxiliá-la, se necessário, neste processo, visto que é um processo muito importante não só para a nutrição da criança, mas também para a saúde e o estabelecimento do vínculo mãe-bebê.

\section{COMPLICAÇÕES NA GRAVIDEZ/PARTO}

Complicações no decorrer da gestação que possam interferir significativamente no processo gestacional e no trabalho de parto se apresentam como um fator de risco para o surgimento de transtornos mentais ${ }^{15}$. Através dessa perspectiva, os artigos 3, 17 e 19 abordam o efeito das complicações no parto na prevalência de DPP. O artigo 18 aborda as complicações no período pré-natal e pós-parto e suas consequências no surgimento de sintomas depressivos ${ }^{10,13,17,20}$.

No artigo 3 foram abordados os dados das mães entrevistadas na pesquisa, separando-as pela presença ou não de sintomas depressivos. As mães que apresentaram complicações no parto tiveram uma prevalência maior de sintomas depressivos (40\%) que as mães que não apresentaram complicações $(23,3 \%)^{20}$.

$\mathrm{O}$ artigo 17 evidenciou resultados parecidos ao do artigo anterior, com um número maior de parturientes depressivas que tiveram complicações durante o parto. O estudo apontou que $33,3 \%$ das 
puérperas deprimidas sofreram de complicações durante o parto, enquanto que em puérperas não deprimidas esse número cai para $17 \%^{17}$.

Seguindo o mesmo raciocínio, o artigo 18 mostrou uma chance 0,77 maior de desenvolver DPP em casos que tiveram complicações médica na gravidez e entre as mães que sofreram complicações no pós-parto o risco de não desenvolver DPP é 0,654 superior. Além disso, esse mesmo estudo mostrou uma prevalência de mulheres que vivenciaram complicações no período gestacional que acabaram desenvolvendo sintomatologia depressiva de $27,9 \%$, em se tratando de complicações no período pós-parto esse número é ainda maior, de $32,14 \%{ }^{15}$.

O artigo 19 mostrou resultados contrários aos demais estudos que apontavam percentuais maiores de complicações obstétricas (na gestação ou parto) entre as puérperas com sintomas depressivos, ou seja, apontou que o percentual de puérperas deprimidas que sofreram complicações foi menor que entre as puérperas não deprimidas, sendo $15,4 \%$ e $25,9 \%$, respectivamente ${ }^{10}$.

Enfim, a maioria dos estudos evidenciaram uma relação entre complicações obstétricas e no pós-parto com os sintomas de DPP, indicando um percentual maior de mães com sintomas depressivos no grupo de mães que sofreram complicações. Sendo assim, o profissional deve estar atento às mulheres que apresentarem essa variável pois elas podem estar mais propensas a manifestarem sintomas depressivos.

\section{ESCOLARIDADE}

Em se tratando de fatores de risco de DPP, diversos autores afirmam a contribuição de baixas condições socioeconômicas para a manifestação dessa patologia ${ }^{23}$. Nesse sentido, os artigos 2, 3, 5, $8,13,15,18$ e 19 abordam a prevalência da variável socioeconômica de escolaridade nas mulheres utilizadas na amostra e sua relação com a

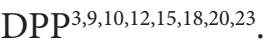

Os artigos 2, 3, 5, 8, 13, 15 e 18 apesar de alcançarem percentuais diferentes, chegaram ao mesmo resultado, evidenciando a relação entre DPP e baixos níveis de escolaridade ${ }^{3,9,12,15,18,20,23}$. No artigo 2, ficou evidenciado uma significante relação entre DPP e ensino fundamental incompleto ${ }^{23}$.

Os artigos 3, 5 e 8 apresentaram números maiores de mulheres com depressão pós-par- to que estudaram até 8 anos se comparados com mulheres que estudaram mais de 8 anos $^{3,18,20}$. No artigo 3 , as mulheres com sintomas depressivos representavam $34 \%$ das mães que estudaram menos de 8 anos. Já entre as que estudaram 8 anos ou mais esse número diminui para $21,7 \%{ }^{20}$. Seguindo essa mesma linha, o artigo 8 apresentou resultados semelhantes aos do artigo 3, com 32,6\% de prevalência de sintomas depressivos entre as puérperas que estudaram menos de 8 anos e $20 \%$ de prevalência nas puérperas que estudaram 8 anos ou mais ${ }^{18}$.

$\mathrm{O}$ artigo 5 apresentou percentuais decrescentes de puérperas com sintomas depressivos em relação aos anos de estudo, sendo evidenciado por $19,5 \%$ de puérperas que estudaram até 8 anos, $11,7 \%$ de puérperas que estudaram de 9 a 11 anos e apenas 8,3\% das mães que estudaram 12 anos ou mais manifestaram sintomas depressivos ${ }^{3}$.

O artigo 13 dividiu a variável escolaridade na pesquisa em dois grupos, mulheres que estudaram menos de 5 anos e mulheres que estudaram 5 anos ou mais, como resultado do estudo sobre essa variável houve maiores chances de ocorrência de sintomas relacionados a DPP em mães que estudaram menos de 5 anos (33,3\%) se comparado as mães que estudaram 5 anos ou mais, representado pelo resultado de $23,8 \%{ }^{9}$.

No artigo 15, o fator escolaridade teve uma atenção especial, tendo se sobressaído neste estudo se comparado à outras variáveis, sendo citado como o principal indicador sociodemográfico relacionado a depressão ${ }^{12}$.

O artigo 19, entre os estudos, foi o que mostrou resultados mais distinto, com um número de puérperas deprimidas maior - de $36,2 \%$ - em mães que estudaram de 9 a 11 anos e um número significativamente menor em mães que estudaram até 8 anos, que foi de $32,1 \%$, no grupo de mães com mais de 12 anos de estudo não houve casos de puérperas deprimidas ${ }^{10}$.

Portanto, a junção dos resultados sobre o fator escolaridade permitiu chegar à conclusão que a grande maioria dos estudos relacionou baixos níveis de escolaridade com a manifestação de sintomas depressivos no período pós-parto. Sabendo disso, o profissional deve ter em mente que mães com menos anos de estudos estão mais vulneráveis à manifestação da doença e por isso os profis- 
sionais devem estar mais atentos aos sintomas da DPP nesses grupos de mães.

\section{ESTADO CIVIL}

Os artigos 1, 3, 8, 16, 18 e 19 abordam a variável sociodemográfica estado civil e sua relação com a sintomatologia da $\mathrm{DPP}^{10,15,16,18,20,25}$. O artigo 1 compõe uma amostra com 6 mães diagnosticadas com DPP, em que 4 delas são casadas e 2 são solteiras, ou seja, $66,7 \%$ e $33,3 \%$, respectivamente, da composição da amostra ${ }^{16}$.

O artigo 3 aborda a variável estado civil dividindo-a em dois grupos, o primeiro sendo composto de solteiras, separadas e viúvas e o segundo por casadas e com relação estável. No primeiro grupo foi observado que $26,7 \%$ do grupo apresentou sintomas depressivos, já no segundo grupo esse número teve uma leve diminuição, sem muita significância, para $24,05 \%{ }^{20}$. O artigo 16 teve resultados também sem muita significância na relação da variável com a DPP, além disso, também não mostrou significância em relação ao tempo de relacionamento com a enfermidade ${ }^{25}$.

Os artigos 18 e 19 mostraram resultados semelhantes entre si, ambos com percentuais de sintomas depressivos em mães que se encontram em relação estável e casadas maiores que os encontrados em mães solteiras ${ }^{10,15}$. No artigo 18 os números de puérperas depressivas foi $18,7 \%$ entre as solteiras, $25,9 \%$ nas mães que se encontravam em uma relação estável, $26,8 \%$ no grupo das mães casadas e $100 \%$ das mães divorciadas, sendo esse último grupo composto por apenas uma mãe, o que justifica o percentual máximo ${ }^{15}$. No artigo 19 os seguintes números de puérperas depressivas foram encontrados: $25 \%$ entre àquelas solteiras, $28,6 \%$ no grupo das puérperas casadas e $35,3 \%$ no grupo daquelas que indicaram estar em uma união consensual ${ }^{10}$.

No artigo 8 foi encontrado resultados contrários aos artigos 18 e 19, mostrando uma prevalência maior de sintomas depressivos naquelas mulheres sem um companheiro. Esse artigo dividiu a variável estado civil em dois grupos, com companheiro - ilustrado com o número de 19,9\% - e sem companheiro, onde foi encontrado sintomas depressivos em $33,9 \%$ das mães ${ }^{18}$.

De modo geral, os artigos ficaram bem divergentes quanto aos resultados sobre essa variável, com artigos que indicaram uma prevalência maior de sintomas depressivos em mulheres com relação estável e casadas, ou seja, com companheiro, do que nas mulheres sem companheiros/solteiras. Além dos artigos que não encontraram uma relação significativa entre estado civil e sintomas depressivos. Portanto, a variável estado civil não mostrou relação direta com a DPP, assim como o tempo de relacionamento do casal, não expressando uma prioridade no rastreamento da doença.

\section{HISTÓRICO PESSOAL E FAMILIAR DE TRANSTORNOS MENTAIS}

A ocorrência de depressão em qualquer momento que preceda a gestação ou o puerpério vem sendo uma variável de efeito significativo e relevante acerca da $\mathrm{DPP}^{12,18}$. Os artigos 3, 5, 8, 9, 13, 15 e 18 abordam a variável de história pregressa de transtornos mentais e/ou histórico familiar de depressão $0^{3,8,9,12,15,18,20}$.

O artigo 3 continha tanto a variável de problema mental anterior quanto problema mental familiar, ambas com os dados disponíveis para análise. Entre as mulheres que passaram por problema mental anterior, $46,2 \%$ delas sofreram sintomas depressivos, já nas mulheres que nunca passaram por problema mental esse número cai para $23 \%$. O mesmo fenômeno ocorre na variável de problema mental familiar, que entre as mulheres com familiares que sofriam ou sofrem de transtornos mentais a prevalência de sintomas depressivos é cerca de 2,5 vezes maior do que as mulheres com familiares sem transtornos mentais, podendo ser um indicativo de herança genética relacionada com a DPP 20

$\mathrm{O}$ artigo 5 estudou a prevalência de sintomas depressivos ao longo da vida, durante a gestação e a ocorrência da depressão. Através da análise dos dados da amostra, o artigo 5 identificou perigo até 3 vezes maior entre as mulheres que se sentiram deprimidas ou tristes nos três últimos meses da gestação e um risco de 33\% maior em gestantes com familiares que tiveram depressão ${ }^{3}$.

Os artigos 8, 9 e 15 analisaram em suas amostras o histórico de depressão nas mulheres e, apesar de apresentarem resultados variados, todos chegaram a mesma conclusão, relacionando a depressão anterior à manifestação da $\mathrm{DPP}^{8,12,18}$. No artigo 8 , $18,1 \%$ das mulheres que não tinham histórico de 
depressão manifestaram sintomas depressivos, já entre as mulheres com histórico de depressão esse número aumenta para $45 \%$, aproximadamente 2,5 vezes maior ${ }^{18}$.

No artigo 9, episódios anteriores de depressão foram relacionados a DPP através da média de pontos das mulheres da escala EPDS, as mães que afirmaram episódio anterior de depressão tiveram uma média da EPFD de 10,5, número que cai drasticamente nas mães que afirmaram não apresentarem episódio anterior de depressão, que tiveram uma média da EPDS de 6,598. $\mathrm{O}$ artigo 15 encontrou efeito significativo da depressão anteriormente à gestação e/ou ao puerpério sobre a ocorrência da $\mathrm{DPP}^{12}$.

Os artigos 9, 13 e 18 apresentaram em seu estudo a variável histórico de transtorno mental/ psiquiátrico, todos indicando uma relação entre histórico de transtorno mental e $\mathrm{DPP}^{8,9,15}$. No artigo 9, as mulheres que tinham algum transtorno psiquiátrico obtiveram uma média maior que as mulheres que não tinham nenhum transtorno psiquiátrico, sendo 9,19 e 6,92, respectivamente seus números na EPDS 8 .

No artigo 13, 48,8\% das mães com histórico pessoal de transtorno mental apresentaram sintomas depressivos, enquanto as mães que não tinham transtorno mental esse percentual caiu para $22,8 \%{ }^{9}$. No artigo 18 a prevalência de puérperas depressivas foi de $33,3 \%$ entre as mães com história de transtorno mental foi de $24,8 \%$ entre as mães sem transtorno mental anterior ${ }^{15}$.

Seguindo esta linha de raciocínio, pode-se concluir que todos os artigos abordados nesta revisão apontaram a relação de histórico de transtorno mental e depressão, tanto pessoal quanto familiar com a presença de sintomas relacionados à DPP. Dessa forma, a equipe de saúde deve estar preparada para acolher a mulher com história de transtornos mentais pessoal ou familiar, visando a prevenção, a detecção precoce e o tratamento da DPP.

\section{IDADE}

De modo geral, todos os artigos englobavam a variável idade, porém apenas oito deles analisaram a relação do fator idade com a DPP, sendo esses os que foram escolhidos para realizar a revisão desta categoria. Os artigos que, entre as variáveis, abordou o fator idade foram os 3, 5, 8, 10, 13, 16,
18 e 19. Todos eles dividiram o fator idade em grupos e observou a prevalência de DPP e sintomas relacionados em cada grupo ${ }^{3,9,10,14,15,18,20,25}$.

Os artigos 3, 8, 13 e 18 foram analisados e tiveram em comum o fato de a prevalência de sintomas depressivos ter sido maior nos grupos com maior idade, de acordo com a divisão utilizada em cada estudo ${ }^{9,15,18,20}$. O artigo 3 dividiu o fator idade em dois grupos, um primeiro grupo de mulheres de 18 a 24 anos e um segundo de 25 a 42 anos, sendo 18 e 42 anos as idades limite da amostra. A diferença percentual de mães que apresentaram sintomas depressivos no artigo foi mínima, de apenas $2 \%$, sobressaindo o grupo de mães de 25 a 42 anos, com $25 \%$ de mães com sintomas depressivos ${ }^{20}$.

$\mathrm{O}$ artigo 8 dividiu sua amostra, de acordo com a idade, em três grupos, um primeiro com mulheres até 19 anos, um segundo com mulher de 20 a 34 anos e um terceiro grupo com mulheres de 35 anos ou mais. O percentual de sintomas depressivos nas mães foi crescente em sintonia com a idade, sendo menor no primeiro grupo $(18,4 \%)$, com um leve aumento no segundo grupo $(20,4 \%)$ e um grande aumento no terceiro grupo $(36,4 \%)^{18}$.

No artigo 13, a amostra foi dividida em mães adolescentes (até 19 anos) e adultas (a partir dos 20 anos), sendo as mães adultas representando $86,2 \%$ da amostra, ou seja, sua grande maioria e também teve um percentual maior, de sintomatologia depressiva nas mães, de $26,5 \%$, enquanto que nas adolescentes esse número foi de $22 \%$, uma diferença não tão elevada' .

No artigo 18 o fator idade foi dividido em grupos de quatro em quatro anos, a partir dos 14 anos até os 46 , ou seja, um grupo de 14 até menores de 18 anos, outro grupo de 18 até menores de 22 anos, e assim sucessivamente. Os percentuais de mães depressivas de cada grupo foram relativamente altos nos grupos até 21 anos, diminuindo nos grupos de 22 a 37 anos e aumentando de modo acentuado dos 38 aos 41 anos e compondo $100 \%$ do grupo de 42 a 45 anos, esse último composto por apenas duas mães, obviamente, ambas depressivas ${ }^{15}$.

Os artigos 16 e 19 estudaram o fator idade de modo diferente dos artigos citados acima, eles apresentam um comparativo da média de idade da amostra com a média de idade de mães depres$\operatorname{sivas}^{10,25}$. No artigo 16 a média de idade da amostra 
foi de 27,1 , já a média de idade das mães com DPP foi de 28,7 , sendo que $17,5 \%$ da amostra apresentou escore sugestivo de DPP ${ }^{25}$. No artigo 19 , a média de idade ada amostra foi de 26,6 , já a média de idade das puérperas depressivas foi inferior à da amostra, de 25,3 anos, contrariando o resultado do artigo $16^{10}$.

$\mathrm{O}$ artigo 5 dividiu sua amostra em 3 grupos, o primeiro grupo consiste em mães de 13 a 24 anos, o segundo grupo é formado por mães de 25 a 29 anos e o terceiro por mães com 30 anos ou mais. Entre os grupos a diferença foi mínima, o primeiro e o terceiro grupo apresentaram resultados iguais quanto ao percentual de mães que apresentaram fatores associados à depressão, $15 \%$ em ambos os grupos, já no segundo grupo esse percentual caiu em dois pontos, ou seja, $13 \%{ }^{3}$.

$\mathrm{O}$ artigo 10 separou as mães com sintomas depressivos e, após a separação, avaliando a prevalência em cada faixa etária, sendo estes divididos em grupos de 5 em 5 anos dos 15 aos 34 anos. A faixa etária que apresentou a maior prevalência foi de 20 a 24 anos, com 39,1\% das mães depressivas, seguido pela faixa etária de 25 a 29 anos, com $25,5 \%$ das mães depressivas, podendo ser explicado pelo fato dessas faixas etárias serem as que ocorrem mais partos ${ }^{14}$.

De acordo com o observado nos artigos, variou muito entre os estudos, não podendo especificar uma faixa etária específica de destaque na prevalência de DPP, apesar de 50\% dos artigos utilizados neste estudo apontaram um percentual maior de mães com sintomatologia depressiva nos grupos de maior idade de cada artigo. Portanto, a idade pode não estar intimamente relacionada a DPP, por isso o profissional da área de saúde que participa da atenção às puérperas não deve especificar uma faixa etária de risco, mas deve prestar atenção na prevalência da doença na sua região e na sua unidade de trabalho, para analisar o surgimento de alguma faixa etária de risco.

\section{PLANEJAMENTO DA GRAVIDEZ}

As mães que não planejaram a gravidez tiveram um destaque na manifestação de sintomas depressivos e o planejamento desta gestação pode diminuir o risco do surgimento da doença $^{12,20}$. Os estudos que utilizaram a variável gravidez planejada foram os artigos $3,5,8,13,17$,
18 e 19, avaliando sua relação com a DPP e com seus sintomas ${ }^{3,9,10,15,17,18,20}$.

$\mathrm{O}$ artigo 3 teve os seguintes números sobre essa variável: $27,7 \%$ de mães que não planejaram a gravidez apresentam sintomas e $17,5 \%$ daquelas mães que planejaram a gravidez manifestaram sintomas característicos da doença, evidenciando a relação da doença com o não planejamento da gravidez ${ }^{20}$.

No artigo 5, apenas $9,7 \%$ que planejaram sua gestação manifestaram sintomas, por esse motivo, neste estudo foi considerado um fator protetivo para a DPP o planejamento da gestação, com uma queda de até $30 \%$ no risco de a puérpera manifestar tal doença quando o recém-nascido é fruto de uma gestação planejada ${ }^{3}$.

$\mathrm{O}$ artigo 8, entre os artigos que avaliaram essa variável, foi o com a maior diferença percentual, sendo $15,1 \%$ e $61,9 \%$, respectivamente, a prevalência de sintomas da depressão nas mães com gravidez planejada e entre mães com gravidez não planejada. Uma diferença tão alta evidencia uma forte tendência da manifestação dos sintomas em casos de não planejamento da gravidez ${ }^{18}$.

O artigo 13 cita a variável gravidez pretendida ao invés de gravidez planejada, apesar das palavras terem significados diferentes, nesta revisão integrativa decidiu-se agrupá-las numa mesma categoria pela proximidade do tema. E assim como nos estudos que citaram gravidez planejada, no artigo 13 a gravidez pretendida foi considerado um fator protetivo, sendo menor o número de mães depressivas entre as mães que pretendiam engravidar (20\%) se comparado às mães que não pretendiam engravidar $(30 \%)^{9}$.

$\mathrm{O}$ artigo 17 dividiu sua amostra em dois grupos, puérperas depressivas e puérperas não depressivas, após essa divisão foi realizado a análise das variáveis. Sobre a variável gravidez planejada, foi possível observar um número mais elevado de mulheres que não planejaram a gravidez no grupo das puérperas depressivas - sendo um número relativamente alto, $66,7 \%$ - que no grupo das puérperas não depressivas, que, apesar ser um número elevado também, de $55,3 \%$, é menor que o achado do outro grupo do estudo ${ }^{17}$.

Os artigos 18 e 19 estão em concordância com os achados em outros estudos no caso da variável gravidez planejada, com o percentual de mulheres com sintomas depressivos maior no grupo 
de mães que afirmaram não ter planejado a gravide $^{10,15}$. O artigo 18 apresentou uma diferença percentual de $6,4 \%$ de sintomas depressivos entre mulheres que planejaram ou não a gravidez, sendo o artigo com a menor diferença percentual, porém, apesar da pequena diferença, o artigo 18 mostra que os sintomas depressivos em mães que não planejaram a gravidez se sobressaíam ${ }^{15}$. No artigo 19 a diferença entre os dois grupos foi um pouco maior - de aproximadamente $15,4 \%$ mas continua na mesma linha de raciocínio dos demais artigos englobados nesta revisão, com um destaque de sintomas depressivos nas mães que não planejaram a gravidez ${ }^{10}$.

Portanto, foi analisado que todos os artigos englobados nesta revisão que continham a variável gravidez planejada disponível para análise mostraram uma relação da DPP com o não planejamento da gravidez. Dessa forma, é importante que os profissionais de saúde atuem no processo de planejamento reprodutivo como um fator protetivo para a não manifestação da doença, e estarem atentos, desde o pré-natal, à aparição de sintomas depressivos relacionados ao não planejamento na gravidez.

\section{RELACIONAMENTO CONJUGAL}

A relação conjugal é apontada como uma importante rede de apoio e no caso de uma relação conflituosa pode ser relacionada a sintomas depressivos e tristeza na mãe $e^{19,21}$. Os artigos $3,6,9$, $11,12,13,15,17$ e 19 abordaram variáveis relacionadas à relação conjugal, como conflitos conjugais, relações conflituosas, falta de apoio do companheiro e satisfação conjugal ${ }^{8-12,17,19-21}$.

O artigo 3 analisou os conflitos, a ocorrência de conflitos conjugais nas mães e sua relação com a DPP. Entre as mulheres que afirmaram ter conflitos conjugais, $20,8 \%$ delas tiveram sintomas depressivos, já entre as mães que afirmaram não ter conflitos conjugais o número foi mais elevado, $36,3 \%$ delas não tiveram sintomas depressivos, não relacionando a ocorrência de conflitos conjugais com $\mathrm{DPP}^{20}$.

Os artigos 6, 9, 12, 13 e 19 analisaram como estava a relação conjugal de acordo com a mulher ${ }^{8-10,19,21}$. No artigo 6 foi observado uma correlação da manifestação da DPP com uma relação conflituosa com o então pai da criança ${ }^{21}$. No arti- go 9 as mulheres que afirmaram ter um relacionamento insatisfatório tiveram uma média de 13,21 na EPDS, um número bem elevado se comparado a média das mulheres que afirmaram ter um relacionamento satisfatório, que foi de $7,2^{8}$. No artigo 12 as participantes do estudo apontaram a relação com o parceiro como uma importante forma de apoio, podendo proporcionar ajuda no período puerperal ${ }^{19}$. No artigo 13 as participantes relataram que a relação com o parceiro se configura como uma importante forma de apoio, através do provimento de ajuda nos cuidados com a criança $\mathrm{a}^{9}$. No artigo $19,7,7 \%$ das puérperas depressivas afirmaram ter um relacionamento ruim com o pai da criança, esse percentual nas puérperas não depressivas cai mais da metade, para 3,7\%, apontando uma certa relação da DPP com um relacionamento ruim ${ }^{10}$.

O artigo 11 verificou uma ligação entre depressão e satisfação conjugal e, além de andarem juntas, elas se mantêm um relacionamento bidirecional. Este estudo teve como resultados que não apenas a depressão age na satisfação conjugal, como também a relação conjugal tem um forte impacto na sintomatologia depressiva, longitudinal e transversalmente ${ }^{11}$. Nesse sentido, pode-se concluir que a qualidade da relação conjugal afeta o nível de DPP e também o surgimento da depressão futuramente.

$\mathrm{O}$ artigo 15 avaliou a qualidade do relacionamento das mulheres com o pai da criança, que foi aferida através do grau de conflito relatado pelas participantes. Os dados encontrados no estudo confirmaram estudos anteriores, que indicam como fator preditivo da DPP os conflitos na relação ${ }^{12}$.

O artigo 17 avaliou, como uma variável de seu estudo, a falta de apoio do companheiro. Foi observado que $29,8 \%$ das parturientes não depressivas afirmaram a falta de apoio do companheiro. Esse percentual sofre um aumento extremamente excessivo para $100 \%$ nas parturientes depressivas, ou seja, todas as parturientes depressivas afirmaram passar pela falta de apoio do companheiro ${ }^{17}$.

Desse modo, pode-se constatar que o relacionamento conjugal se correlaciona com a DPP, relações conflituosas, ruins e insatisfatórias podem ser consideradas fatores de risco para a manifestação da doença, e satisfação e relacionamentos bons com o parceiro pode ser considerado um fator de proteção 
contra a doença. Portanto, o profissional deve observar e questionar a mãe sobre o relacionamento com o pai da criança e, se necessário, influenciar a mulher a realização de meios que possam melhorar esse relacionamento, se que mostrou de suma importância para a prevenção e o tratamento da DPP.

\section{RENDA FAMILIAR}

Renda familiar representa uma importante variável socioeconômica que foi utilizada em vários estudos de campo. Os artigos 2, 3, 5, 10, 11, 13, $15,16,18$ e 19 abordaram o tema renda familiar, cada um ao seu modo, e apresentaram resultados diversos ${ }^{3,9-12,14,15,20,23,25}$.

Os artigos 2, 15, 16 e 18 não encontraram associação entre a depressão e a baixa renda ${ }^{12,15,23,25}$. O artigo 16 utilizou, para a avaliação da ligação entre DPP e renda familiar, uma divisão da amostra por salários mínimos - o tipo de divisão mais utilizado para o estudo dessa variável - um primeiro grupo com mães com renda familiar menor que um salário mínimo, um segundo grupo com mães com renda familiar de 2 a 3 salários mínimos e um terceiro grupo com mães que tinham renda familiar maior que 3 salários mínimos. O primeiro grupo com $21,7 \%$ de mães depressivas, o segundo com $7,7 \%$ e o terceiro com $25 \%$ de mães depressivas, sendo o último o com o maior percentual de mães depressivas no grupo ${ }^{25}$. Assim como o artigo 16, o artigo 18 também dividiu sua amostra por salários mínimos da mesma forma, com três grupos e, coincidentemente, apesar de números diferente o resultado final foi semelhante com os encontrados no artigo 16, com o maior percentual de mães com sintomas depressivos no terceiro grupo $(29,4 \%)$, seguido pelo primeiro grupo $(25,9 \%)$ e finalizando com o segundo grupo $(23,1 \%)^{15}$.

Os artigos 3, 13 e 19 apontaram uma baixa ligação da renda familiar com a depressão, com resultados divergentes, ${ }^{9,10}$. $\mathrm{O}$ artigo 3 dividiu analisou a renda familiar de sua amostra através da divisão em 2 grupos, mães que ganham até 1 salário mínimo e mães que ganham mais de 1 salário mínimo, com um percentual maior de mães depressivas entre as mães que ganhavam até 1 salário mínimo, 28,85\% delas apresentaram sintomatologia depressiva, enquanto apenas $22,15 \%$ das mães que ganhavam mais de 1 salário mínimo apresentaram sintomatologia depressiva ${ }^{20}$.
No artigo 13 o autor avaliou o ganho de renda das mães e sua relação com a aparição de sintomas depressivos. Entre as mães com renda fixa, 28,4\% delas apresentaram sintomas depressivos, já entre as mães sem renda fixa $22,4 \%$ delas apresentaram sintomas, uma diferença de 6 pontos percentuais ${ }^{9}$.

No artigo 19 foi avaliado a média salarial das puérperas depressivas e das puérperas não depressivas e foi comparado as duas médias. A média salarial maior foi das puérperas não depressivas, sua média era de $\mathrm{R} \$ 1.085,80$, já entre as puérperas depressivas houve uma queda de aproximadamente de $\mathrm{R} \$ 25$, sendo sua média de $\mathrm{R} \$ 1060,90^{10}$.

Os artigos 5, 10 e 11 encontraram uma ligação entre DPP e renda familiar, mais especificamente em casos de baixa renda. No artigo 5, verificou-se um coeficiente de relação negativo, ou seja, as variáveis se relacionam e andam juntas, mas em direções opostas. Na medida que a renda familiar aumentou a prevalência da aparição de sintomas depressivos diminuía, fenômeno também observados nos artigos 10 e 11, que relacionaram a renda familiar à depressão em seus estudos e adicionaram as dificuldades financeiras como um fator de risco para a manifestação da doença $a^{5,11,14}$.

De acordo com os resultados encontrados nos estudos, não se pôde concluir a ligação de DPP e renda familiar. Apesar dessa ligação ser apontada em alguns estudos, muitos estudos não conseguiram apontar essa relação e outros mostraram uma baixa associação, sem tanta significância. Com isso, o profissional de saúde não pode incluir baixa renda familiar como um fator de risco para o desenvolvimento da depressão pós-parto, porém, é importante que continue avaliando essa variável, já que esta revisão não pôde excluir a associação da variável com a DPP.

\section{TIPO DE PARTO}

Algumas pesquisas anteriores a esse estudo tentaram estabelecer uma relação entre a DPP e o tipo de parto (normal ou cesárea) à qual as mulheres se submeteram no nascimento de seus filhos ${ }^{22}$. Assim, os artigos 3, 4, 10, 15, 18 e 19 avaliaram a correlação do tipo de parto com a manifestação de sintomas depressivos e os resultados dos estudos foram bem variados ${ }^{10,12,14,15,20,22}$.

Os artigos 3 e 4 encontraram uma leve relação entre o parto cesárea e a DPP, evidenciado pelo percentual maior de mães com sintomas depressivos entre 
as mães que foram submetidas a parto cesárea ${ }^{20,22}$. No artigo 3, 28,6\% das mulheres que foram submetidas a parto cesárea apresentaram sintomas sugestivos de depressão e 17,95\% das mães que foram submetidas a parto vaginal apresentaram sintomas sugestivos ${ }^{20}$. No artigo 4, a diferença ente os dois grupos foi um pouco menor, sendo $25,3 \%$ de casos de DPP entre as mulheres com parto cesárea e 19,5\% entre as mulheres que tiveram seus filhos por parto vaginal ${ }^{22}$.

Os artigos 10 e 15 não apresentaram resultados significativos para relacionar a DPP e o tipo de parto, ou seja, não mostrou efeitos significativos sobre a doença ${ }^{12,14}$. No artigo 10 , as variáveis obstétricas deram quase que iguais quanto ao tipo de parto. No grupo das mães depressivas, $49 \%$ tiveram parto normal e $51 \%$ tiveram parto cesárea ${ }^{14}$.

Os artigos 18 e 19 mostraram uma leve relação da DPP com o parto normal, ou seja, esses dois estudos evidenciaram um percentual maior de mulheres depressivas entre as mães que tiveram parto normal ${ }^{10,15}$. No artigo 18 a diferença percentual de mães com sintomas depressivos entre as duas variáveis foi de 3,7 pontos percentuais, se destacando o conjunto de mães que tiveram parto normal, com $27,3 \%$ de mães com sintomas depressivos ${ }^{15}$. O artigo 19 apresentou resultados mais significativos, com uma diferença de quase 10 pontos percentuais, destacou-se as mães que tiveram parto vaginal com $35,7 \%$ delas puérperas deprimidas, enquanto entre as mães submetidas a parto cesárea a proporção de puérperas deprimidas cai para $25 \%$ das mães ${ }^{19}$.

Nesse sentido, pode-se concluir que a DPP não estabelece uma relação com o tipo de parto das mães, pela divergência de resultados encontrados nos estudos. Com isso, aquele profissional que atuar na área não deve especificar um grupo específico de rastreamento de DPP através do tipo de parto, já que os estudos não puderam confirmar significância estatística.

\section{Conclusão}

Foi evidenciado que a DPP tem diversos fatores que podem influenciar seu surgimento, podendo servir de base para a identificação de um grupo de risco. Além disso, fatores de risco já relacionados a depressão, como estado civil e renda familiar, não foi possível confirmar a associação com a doença após a análise dos artigos. Com base nisso, a assistência em saúde deve buscar identificar nas puérperas fatores relacionados ao desenvolvimento da DPP, visando o bem-estar tanto da mãe quanto da criança.

Assim, o perfil sociodemográfico e psicossocial das mulheres tem servido como uma forma de detecção precoce da depressão, através da identificação desde o pré-natal de fatores de risco que possam aumentar a probabilidade da manifestação da doença proporcionando ações de promoção e prevenção.

Os resultados permitiram avaliar as variáveis que mais se relacionavam com o surgimento de sintomas relacionados a DPP. Ao analisar os estudos, foi possível confirmar a relação da DPP com a interrupção precoce da amamentação e dificuldades de realizar a mesma, complicações na gestação e no parto, escolaridade baixa, não planejamento da gravidez, histórico tanto pessoal quanto familiar de transtornos mentais e relacionamento conjugal conflituoso, além disso nesta revisão algumas variáveis não estabeleceram relação com a DPP, sendo elas estado civil, idade, renda familiar e tipo de parto.

Por fim, ao verificar os resultados finais da análise dos estudos foi ressaltado que tanto as variáveis que se correlacionaram quanto as variáveis que não conseguirem estabelecer uma associação com a depressão não podem ser excluídas de estudos futuros e da avaliação na assistência de saúde, pois é importante sempre estar atento às mudanças na correlação das mesmas com a doença.

Sugere-se a importância do estabelecimento de um perfil sociodemográfico e psicossocial com maior probabilidade de desenvolver DPP. Assim é necessário que ocorra a divulgação do conhecimento sobre o tema aos profissionais da área, sendo que pela quantidade de estudos que estudaram de modo mais aprofundado essas variáveis, os profissionais da área têm interesse em conhecer esses fatores de risco para facilitar a prestação de uma assistência de qualidade.

Sendo assim, é possível concluir que a identificação de fatores que possam desencadear a DPP pode ser o melhor meio de prevenção, pois facilita o rastreio de mulheres e a realização de ações de promoção e prevenção, além de facilitar a prestação de um acolhimento e uma assistência de qualidade visando diminuir a prevalência e tratar o mais precocemente possível a doença. 


\section{Referências}

1. Teng CT, Humes EC, Demetrio FN. Depressão e comorbidades clínicas. Rev. psiquiatr. clín. (São Paulo). 2005;32(3):149-59.

2. Bahls SC. Aspectos clínicos da depressão em crianças e adolescentes. J. pediatr. (Rio J.). 2002;78(5):359-66.

3. Hartmann JM, Mendoza-Sassi RA, Cesar JA. Depressão entre puérperas: prevalência e fatores associados. Cad. Saúde Pública. 2017;33(9):e00094016.

4. Brocchi BS, Bussab VSR, David V. Depressão pós-parto e habilidades pratigmáticas: comparação entre gêneros de uma população brasileira de baixa renda. Audiol. commun. res. 2015;20(3):262-68

5. Silva CS, Lima MC, Serqueira-de-Andrade LAS, Oliveira JS, Monteiro JS, Lima NMS et al. Associação entre a depressão pós-parto e a prática do aleitamento materno exclusivo nos três primeiros meses de vida. J. Pediatria (Rio J.). 2017;93(4):356-364.

6. Filha MMT, Ayers S, Gama SGN, Leal MC. Factors associated with postpartum depressive symptomatology in Brazil: The Birth in Brazil National Research Study, 2011/2012. J. affect. disord. 2016;194:159-67.

7. Frizzo GB, Piccinini CA. Interação mãe-bebê em contexto de depressão materna: aspectos teóricos e empíricos. Psicol. estud. 2005;39(4):47-55.

8. Abuchaim ESV, Caldeira NT, Lucca MM, Varela M, Silva IA. Depressão pós-parto e autoeficácia materna para amamentar: prevalência e associação. Acta Paul. Enferm. 2016;29(6):664-70

9. Brito CNO, Alves SV, Ludermir AB, Araújo TVB. Depressão pós-parto entre mulheres com gravidez não pretendida. Rev. saúde pública. 2015; 49(33):01-09.

10. Angelo RCO, Sabino LF, Schwingel PA, Lima APO, Zambaldi CF, Cantilino A, et al. Dor e fatores associados em puérperas deprimidas e não deprimidas. Rev. dor. 2014;15(2): 100-6.

11. Hollist CS, Falceto OG, Seibel BL, Springer PR, Nunes NA, Fernandes CLC et al. Depressão pós-parto e satisfação conjugal: impacto longitudinal em uma amostra brasileira. Rev. bras. med. fam. comunidade. 2016;11(38):01-13.

12. Morais MLS, Fonseca LAM, David VF, Viegas LM, Otta E. Fatores psicossociais e sociodemográficos associados à depressão pós-parto: Um estudo em hospitais público e privado da cidade de São Paulo, Brasil. Estud. psicol. (Campinas).2015;20(1):40-49.

13. Matos JM, Silva VLQ, Rosa WAG, Oliveira ISB. Análise da depressão pós-parto no período puerperal e sua relação com o aleitamento materno. Revista de Iniciação Científica da Libertas 2013;3(1):50-66.
14. Boska GA, Wisniewski D, Lentsck MH. Sintomas depressivos no período puerperal: identificação pela escala de depressão pós-parto de Edinburgh. J. nurs. health. 2016;1(1):38-50.

15. Soares YKC, Gonçalves NPC, Carvalho CMS. Avaliação da depressão pós-parto: prevalência e fatores associados. Rev. interd. 2015;8(4):40-46.

16. Greinert BRM, Carvalho ER, Capel H, Marques AG, Milani RG. A relação mãe-bebê no contexto depressão pós-parto: Estudo qualitativo. Saude e pesqui. 2018;11(1):81-88.

17. Silva DD, Bernardes DR, Carvalho DTC, Bittencourt GRBVR, Portugal JCA. Incidência de depressão pós-parto no município de Campos do Goytacazes. Revista Científica da FMC. 2015;10(2):21-24.

18. Silva MAP, Demitto M, Agnolo C, Torres M, Carvalho $\mathrm{M}$, Pelloso S. Tristeza materna em puérperas e fatores associados. Rev. port. enferm. saúde mental. 2017;18:8-13.

19. Manent MV, Rodrigues OMPR. Maternidade e trabalho: associação entre depressão pós-parto, apoio social e satisfação conjugal. Pensando fam. 2016;20(1):99-111.

20. Monteiro KA, Godoi BN, Toledo OR, David FL, Avelino MM, Moraes EV. Evidências de sintomatologia depressiva no pós-parto imediato. Rev. bras. ciênc. saúde. 2018;24(4):379-388.

21. Santos MAR, Goetz ER, Sicco GP, Fernandes HGS, Medeiros M, Melo NEB, et al. Perfil epidemiológico de puérperas com quadro de depressão pós-parto, em unidades de um município da serra catarinense, SC. Rev. AMRIGS. 2017;61(1):30-34.

22. Biscegli TS, Silva GS, Romualdo PF, Oliveira MS, Silva BR, Solim F. Depressão pós-parto e tipo de parto: perfil de mulheres atendidas em um hospital escola. Rev. cuid. 2017;11(1):59-65.

23. Melo SB, Jordão RRR, Guimarães FJ, Perrelli JGA, Cantilino A, Sougey EB. Sintomas depressivos em puérperas atendidas em unidades de saúde da família. Rev. bras. saúde mater. infant. 2018;18(1):171-177.

24. Greinert BRM, Milani RG. Depressão pós-parto: uma compreensão psicossocial. Revista Psicologia: teoria e prática. 2015;17(1):26-36.

25. Oliveira MJM, Dunningham W. Prevalência e fatores de risco relacionados a depressão pós-parto em salvador. Rev. bras. neurol. psiquiatr. 2015;19(2):72-83. 